\title{
Durkheim e Bourdieu: aproximações e distanciamentos
}

Rodolfo Ferreira da Silva ${ }^{1}$

\section{RESUMO}

O presente ensaio tem por objetivo apresentar de forma sucinta, alguns dos principais aspectos constitutivos do campo de investigação da Sociologia sob a ótica de dois autores. O primeiro, um dos "clássicos da Sociologia”, Émile Durkheim, que viveu na França, nos séculos XIX e XX. Para ele, a Sociologia, enquanto ciência do social coloca como uma das suas principais preocupações a compreensão daquilo que "permite" o social, ou seja, o que faz com que os indivíduos se reúnam em sociedade. O Segundo, o autor contemporâneo Pierre Bourdieu, que deu uma importante contribuição para o pensamento sociológico partir da sua "teoria da ação". Assim, buscamos através deste breve ensaio conjugar as aproximações e dos distanciamentos destes autores, destacando sua importância para o campo de investigação sociológica.

Palavras-chave: Émile Durkheim; Pierre Bourdieu; Sociologia; Teoria da Ação; Habitus; Campo.

\section{ABSTRACT}

The present paper aims to present briefly some of the main constituent aspects of the research field of Sociology from the perspective of two authors. The first, one of the "classics of sociology," Émile Durkheim, who lived in France in the nineteenth and twentieth centuries. For him, Sociology, as a social science, places as one of its main concerns the understanding of what "allows" the social, that is, what causes

\footnotetext{
${ }^{1}$ Professor de História e Sociologia da rede pública estadual do Rio de Janeiro. Graduado em História pela UFRJ, com especialização em História do Século XX pela UCAM. Mestrando em Ciências Sociais na UERJ, com pesquisa na área de dependência química e processos de tratamento e recuperação, sobretudo na irmandade de Narcóticos Anônimos. E-mail: rodolfoferreirasilva1974@gmail.com.
} 
individuals to meet in society. The second, the contemporary author Pierre Bourdieu, who made an important contribution to sociological thinking from his "theory of action." Thus, we seek through this brief article to conjugate the approximations and distances of these authors, highlighting their importance for the field of sociological investigation.

Keywords: Émile Durkheim; Pierre Bourdieu; Sociology; Theory of Action; Habitus; Field.

$\mathrm{O}$ século XIX é marcado por profundas transformações no mundo ocidental. A segunda fase da Revolução Industrial (1850-1870) provocou uma redefinição nos processos produtivos, implementando a partir da introdução de novas matrizes energéticas, uma espantosa aceleração na capacidade de reprodução dos capitais, como também promoveu o aprofundamento da deterioração das condições de vida de uma parte significativa da sociedade europeia, a saber, a nascente classe operária. Se por um lado o processo de industrialização provocou um incremento nas relações comerciais e assegurou a hegemonia econômica da burguesia, por outro, trouxe no seu bojo novas formas de organização e contestação por parte dos trabalhadores, submetidos a cargas de trabalho extremamente extensas e penosas.

O século XIX também se destaca por uma série de inovações tecnológicas, como o motor à explosão, o cinema e a lâmpada incandescente, bem como pela percepção de que a humanidade caminhava no sentido de uma evolução. O evolucionismo é uma das marcas desse período, seja no campo religioso - Kardec publica em 1864 O Evangelho Segundo o Espiritismo -, seja no campo científico - Darwin publica em 1859 A Origem das Espécies. Foi nesse quadro que Augusto Comte surge com a sua "filosofia positiva", sustentando a ideia de que os fenômenos sociais, tais quais os fenômenos naturais e biológicos, são passíveis de observação e compreensão. A “física social”, posteriormente 
chamada de Sociologia, nascia sob o signo de uma "ciência positiva", que deveria incorporar o método de observação das ciências naturais para apreensão da realidade social.

A Sociologia, portanto, pode ser compreendida como uma "ciência do conflito", uma vez que o seu nascimento data exatamente de um momento efervescente e conflituoso, tendo a configuração das relações sociais sofrido uma série de mudanças diante do quadro provocado pelo avanço da industrialização e das mudanças daí decorrentes nas relações de trabalho, no processo de urbanização e nas novas formas de sociabilidade e configuração espacial, provocadas pela consolidação do sistema capitalista. A obra Germinal, de Émile Zola, de 1885, é um belo exemplo dos conflitos e tensões que caracterizaram esse período:

\footnotetext{
Tudo se aniquilava no fundo desconhecido das noites obscuras; só percebia, muito ao longe, os altos-fornos e as fornalhas de coque. Estas, baterias de cem chaminés erguidas obliquamente, alinhavam rampas de chamas rubras, enquanto as duas torres, mais à esquerda, ardiam, azuis, em pleno céu, como tochas gigantescas. Era uma tristeza de incêndio, não havia no horizonte ameaçador outros astros elevando-se a não ser esses fogos noturnos dos países da hulha e do ferro (ZOLA, 1972, p. 37).
}

Nesse quadro, a Sociologia surge como uma ciência que proporá um tratamento científico às questões sociais, levantando assim uma série de questões. Como acessar o social? Como é possível a sociedade? Estas seriam as questões centrais da Sociologia.

O presente ensaio tem por objetivo apresentar alguns dos principais aspectos constitutivos do campo de investigação da Sociologia sob a ótica de dois autores. O primeiro, um dos “clássicos”, Émile Durkheim, que viveu na França, nos séculos XIX e XX. Para ele, a Sociologia, enquanto ciência do social coloca como uma das suas principais preocupações a compreensão daquilo que "permite" o social, 
ou seja, o que faz com que os indivíduos se reúnam em sociedade. $\mathrm{O}$ Segundo, o autor contemporâneo Pierre Bourdieu, que deu uma importante contribuição para o pensamento sociológico partir da sua "teoria da ação".

Dessa forma, tendo sempre em consideração os limites que se impõem a um trabalho dessa natureza, nossa proposta caminha no sentido de apontar algumas questões que estão na base do pensamento desses dois intelectuais. Conscientes da impossibilidade de esgotarmos o tema, procuramos levantar aqui algumas questões que consideramos relevantes para o entendimento das aproximações e dos distanciamentos que se podem estabelecer entre esses autores. Como veremos, existem alguns aspectos na teoria de Bourdieu que foram marcados pelo pensamento de Durkheim.

Assim, partiremos inicialmente para a apresentação de alguns aspectos da teoria de Durkheim que foram incorporados ou até mesmo superados por Bourdieu. Posteriormente, apresentaremos alguns aspectos da teoria de Bourdieu, que foram influenciados pelas reflexões de Durkheim. Finalmente, nas nossas conclusões, pretendemos apresentar uma síntese daquilo que foi discutido ao longo do trabalho e as nossas impressões sobre os referidos autores.

Dessa forma, esperamos poder contribuir, ainda que de maneira bastante introdutória, para o debate sobre esses autores considerados fundamentais para a compreensão das relações sociais como um todo e da Sociologia em especial, destacando as aproximações e cisões entre eles.

\section{Émile Durkheim}

O século XIX é fortemente marcado por uma noção evolucionista e cientificista, na qual a ciência consagraria a noção de que 
a verdade é igual ao fato. A busca da verdade, ideal perseguido pela História e pela ciência natural, distingue verdade de erro. A História, enquanto disciplina, nesse período, assume um compromisso com uma perspectiva narrativa e linear, com a descrição dos fatos e a "sacralização" das fontes oficiais como uma expressão da verdade. A constituição da Sociologia, enquanto ciência, ou seja, a sua institucionalização, pressupunha o estabelecimento de procedimentos estruturados e duradouros. Da mesma forma que, para a História, aquilo que não está referendado pela documentação oficial não serviria como fonte histórica, para a Sociologia, o que não estiver no reino do observável, é mentira. Assim, o século XIX consagra a ideia de um projeto de Sociologia como uma ciência empírica. Para Durkheim, a ciência se constrói com fatos:

E todavia os fenômenos sociais são coisas e devem ser tratados como coisas. [...] Os fenômenos sociais apresentam incontestavelmente tal caráter. Não nos é dada a ideia que os homens formulam a respeito do valor; esta é inacessível, e o que nos é dado são os próprios valores que se trocam realmente no decorrer das relações econômicas. Não é esta ou aquela concepção do ideal moral; é o conjunto de regras que determinam efetivamente a conduta (DURKHEIM, 1995, p. 24).

Para Durkheim, o fato social é coercitivo, exterior e geral. O indivíduo se sujeita à sociedade que foi criada por ele e para ele. Dessa forma, a troca de autonomia por uma maior sensação de segurança social, na medida em que este indivíduo está inserido socialmente, é algo natural.

Se, com o tempo, esta coerção deixa de ser sentida, é porque pouco a pouco dá lugar a hábitos, a tendências internas que a tornam útil, mas que não a substituem senão porque dela derivam (DURKHEIM, 1995, p. 05). 
O fato social não é soma, mas a resultante das vontades individuais. Durkheim, assim, estabelece uma crítica ao utilitarismo, fruto exclusivamente do interesse, defendendo um individualismo ancorado no sentido universal de humanidade. Aqui, o que move o indivíduo não é o egoísmo ou interesse meramente econômico, mas a simpatia por tudo o que é humano, um sentimento de pertencimento, de empatia, entendida como a capacidade de se colocar no lugar do outro.

O melhor do indivíduo é a sociedade nele internalizada. O indivíduo deseja a sociedade, que é boa para ele, uma vez que ele não pode existir fora dela. Ao ser "incorporado" pela sociedade, esta ultrapassa o indivíduo que não pode negá-la sem negar a si próprio. Aqui reside o objetivismo de Durkheim, que coloca a sociedade como algo natural, imanente à vontade individual. Este desejo será moldado através do processo de educação. Dessa forma, a sociedade é uma criação coletiva dos indivíduos, com regras coercitivas e exteriores, a fim de garantir a coesão social. Através da educação, estas regras são internalizadas e passam a ser desejadas. Seguindo uma tradição francesa, os indivíduos são formatados socialmente.

Ao longo da nossa história constituiu-se um conjunto de ideias sobre a natureza humana, a importância respectiva de nossas diferentes faculdades. O direito e o dever, a sociedade, o indivíduo, o dever, o progresso e a ciência, a arte, etc., ideias que se encontram na base do nosso espírito nacional; toda educação, tanto a do rico quanto a do pobre, tanto a que conduz às profissões liberais quanto a que prepara para as funções industriais, tem como objetivo fixá-las na consciência (DURKHEIM, 2011, p. 52).

O todo social, segundo Durkheim, é formado a partir do entendimento desta constituição não como mera função mecânica, mas como ação organizada a partir de solidariedades consentidas socialmente entre grupos e indivíduos morais. Para ele, o conceito de moral de cada povo é determinado pelo seu momento histórico. Assim, 
existe uma moral comum, geral a todos os homens e, portanto, objetiva, pertencente a uma coletividade. Embora reconheça a existência de uma moral individual, sua preocupação é com a moral que designa como objetiva definida como um conjunto de máximas morais, ou seja, regras de conduta.

É, portanto, bem certo que as ordens da moral, por pouco que elas sejam complexas, não tiveram primitivamente como fim o interesse da sociedade. Aspirações estéticas, religiões, paixões de toda espécie, mas sem objetivo utilitário, puderam também lhes dar origem. Sem dúvida, uma vez que elas existem, uma seleção se estabelece entre elas. As que perturbam sensivelmente a vida coletiva são eliminadas; porque, de outra maneira, a sociedade onde elas se produzem não poderia durar e, de toda maneira, elas desapareceriam com elas (DURKHEIM, 2015, p. 33).

Para Durkheim, a construção das categorias fundamentais à compreensão da sociedade é o resultado de um grupo próprio - e não apenas o relacionamento social entre homens - que defina sua identidade a partir do compartilhamento de estruturas simbólicas e normativas. A tarefa da ciência é desvendar o que está oculto, não visível no social, descobrir onde o social está revelado. A subjetividade, portanto, é social. Para compreender a subjetividade, precisamos perceber a sua objetivação através das instituições sociais e regras de controle. O homem, assim, é um ser "dual”. Ao mesmo tempo individual, com um campo de ação limitado, e social, ou seja, a sociedade, aquilo que deve ser apreendido pela observação.

Ao contrário, se as categorias são, como pensamos, representações essencialmente coletivas, elas traduzem antes de tudo estados da coletividade: dependem da maneira com esta é constituída e organizada, de sua morfologia, de suas instituições religiosas, morais, econômicas etc. Há portanto, entre essas duas espécies de representações toda a distância que separa o individual do social, e não se pode mais derivar as segundas das primeiras, como tampouco se pode deduzir a sociedade do indivíduo, o todo da parte, o complexo do 
simples. A sociedade é uma realidade sui generis: tem suas características próprias que não se encontram da mesma forma, no resto do universo. As representações que a exprimem, tem, portanto, um conteúdo completamente distinto das representações puramente individuais, e podemos estar certos de antemão de que as primeiras acrescentam algo às segundas (DURKHEIM, 1996, p. 216).

A fim de confirmar a prevalência do social sobre o individual, ou se preferirmos da objetividade sobre a subjetividade, da estrutura sobre a agência, Durkheim se debruçou sobre os mais diversos objetos, das religiões primitivas aos fatos morais e a divisão social do trabalho nas sociedades complexas, passando pela educação, até chegar a um objeto de análise pertencente quase que exclusivamente à psicologia, que é o suicídio. Aqui, Durkheim pretende demonstrar como, até mesmo o mais dramático e aparentemente solitário momento, que é o do extermínio físico da própria vida, pode ter implicações e explicações sociais. Segundo ele:

[...] De fato, se, em vez de enxergá-los apenas como acontecimentos particulares, isolados uns dos outros e cada um exigindo um exame à parte, considerarmos o conjunto dos suicídios cometidos numa determinada sociedade durante uma determinada unidade de tempo, constaremos que o total assim obtido não é uma simples soma de unidades independentes, uma coleção, mas que constitui por si mesmo um fato novo e sui generis, que tem sua unidade e individualidade, por conseguinte sua natureza própria, e que, além do mais, essa natureza é eminentemente social. (DURKHEIM, 2000, p. 17).

Como último aspecto da teoria de Durkheim que gostaríamos de abordar, surge a questão da sua relação com a História. Tendo como referência os pontos que destacamos na introdução, do contexto, do ambiente em que Durkheim escreve, percebemos como o mesmo se inscreve numa perspectiva histórica, na medida em que está preocupado em refletir sobre as transformações do seu tempo, como a questão da divisão social do trabalho e as novas relações de trabalho advindas da 
segunda Revolução Industrial, bem como uma nova forma de solidariedade decorrente deste fato. Durkheim não nos parece preocupado com a construção de uma teoria do social "abstrata", mas sim em identificar as mutações que ocorrem no tecido social a partir de dados empíricos, de processos históricos passados e/ou em curso, através de uma análise sincrônica, descobrindo as causas que suscitaram novas funções sociais. Robert N. Bellah nos informa que: "at several points Durkheim went so far as to question whether or not sociology and history could in fact be two separate disciplines." (BELLAH, 1959, p. 448). ${ }^{2}$

Segundo ainda o referido o autor, Durkheim percebia a necessidade de uma contextualização histórica dos seus objetos de pesquisa. Para ele, essa percepção partia da premissa de que a compreensão dos fenômenos estudados não poderia estar "descolada” da realidade na qual estavam inseridos.

But Durkheim did not merely preach. Almost all of his own research drawn heavily from historical and ethnological sources and are in fact organized in a historical framework. This is true, for example, of his sociology of the family, his treatment of the division of labor, his theory of punishment (...) (BELLAH, 1959, p. 448-449). ${ }^{3}$

Dessa forma, procuramos, embora de maneira extremamente resumida, destacar alguns pontos que consideramos fundamentais na Sociologia de Durkheim. A questão da razão e da "fé" na ciência, a construção do objeto a partir da observação, a prevalência do social e a influência do conhecimento histórico, são algumas questões que pretendemos levantar. A seguir, abordaremos alguns aspectos da obra de

\footnotetext{
2 "Em vários pontos, Durkheim chegou a ponto de questionar se a sociologia e a história poderiam, de fato, ser duas disciplinas separadas." (minha tradução).

3 "Mas Durkheim não apenas pregou. Quase toda a sua própria pesquisa foi extraída de fontes históricas e etnológicas e, de fato, está organizada em um contexto histórico. Isto é verdade, por exemplo, de sua sociologia da família, seu tratamento da divisão do trabalho, sua teoria da punição (...)" (minha tradução).
} 
outro sociólogo, Pierre Bourdieu, para então reunirmos na parte final os aspectos de Durkheim que encontramos na obra de Bourdieu, seja para referenciá-lo, seja para superá-lo.

\section{Pierre Bourdieu}

Pierre Bourdieu, sociólogo francês, é um dos principais nomes da Sociologia contemporânea. É inegável o papel de destaque que exerceu e ainda exerce na teoria sociológica atual. Das teorias clássicas da Sociologia, Bourdieu procura assimilar conhecimentos que julga relevantes para o desenvolvimento da Sociologia enquanto ciência.

Bourdieu articula dialeticamente ator e estrutura, propondo uma mediação na qual o sujeito surge como um produto da História, do campo social, das experiências acumuladas, da trajetória. Assim, propõe uma superação do método objetivo e fenomenológico, através de uma articulação dialética entre o agente e a estrutura.

Para ele, as práticas sociais são processos dinâmicos, nos quais a objetividade se enraíza na e pela experiência subjetiva. Práticas e comportamentos são subjetivados pelo indivíduo, que redundam na objetividade, num processo de relação dialética entre o indivíduo e a sociedade.

A construção do objeto se dá de maneira concomitante à construção dos conceitos, para que seja possível a apreensão das práticas sociais em sua gênese e especificidade. Bourdieu propõe uma prática científica relacional entre a subjetividade e a objetividade. Sob esta ótica, ganham força estudos acerca da microrrealidade e do cotidiano, como espaço privilegiado de práticas sociais estruturadas pelos agentes.

Para Bourdieu, o objetivismo e o estruturalismo carecem de uma teoria da ação. Dessa forma, segundo essa perspectiva, o agente se vê "refém" das estruturas: "O agente social aparece, portanto, como mero 
executante de algo que se encontra objetivamente programado e que lhe é exterior." (ORTIZ, 1983, p. 11). Bourdieu, então, vai além dessas teorias, introduzindo a questão do poder.

A crítica de Bourdieu ao objetivismo e ao conhecimento fenomenológico procura estabelecer uma teoria da prática onde o agente social é sempre considerado em função das relações objetivas que regem a estruturação da sociedade global (ORTIZ, 1983, p. 19).

Para Bourdieu, a dinâmica social se dá no interior de um campo, um espaço onde os agentes encontram-se em disputa pela hegemonia através da aquisição de capital, seja ele simbólico, cultural e/ou econômico.

\begin{abstract}
Compreender a gênese social de um campo, e apreender aquilo que o sustenta, do jogo de linguagem que nele se joga, das coisas materiais e simbólicas em jogo que nele se geram, é explicar, tornar necessário, subtrair ao absurdo do arbitrário e do não-motivado os atos dos produtores e as obras por eles produzidas e não, como geralmente se julga, reduzir ou destruir (BOURDIEU, 2010, p. 69).
\end{abstract}

Nesse sentido, a compreensão do jogo de forças presentes no tecido social só pode ser apreendida na sua relação com o campo analisado. O campo é delimitado por valores, capital simbólico que lhe dá sustentação. Não existe neutralidade na ação. É um espaço das dinâmicas sociais regidas pelos conflitos entre os atores.

Essas lutas resultam da tendência de todo campo de se reproduzir. Por exemplo, o sistema de ensino é visto por Bourdieu como empreendimento da cultura de classes. Ele sustentou que a cultura escolar, dominada pela cultura burguesa através de códigos comportamentais, linguísticos e intelectuais, reproduz as ilusões (illusio) necessárias ao funcionamento do campo e à manutenção do sistema: as crenças compartilhadas em um campo (THIRY-CHERQUES, 2006, p. 38). 
A cada campo corresponde um habitus próprio do campo. O campo estrutura o habitus e o habitus estrutura o campo. O habitus é objetivo e subjetivo. A objetividade, nesse sentido, não é a única a gerar práticas sociais. O habitus é a incorporação ou a internalização da estrutura social, enquanto o campo é a exteriorização ou objetivação do habitus.

O habitus se apresenta, pois, como social e individual: referese a um grupo ou a uma classe, mas também ao elemento individual; o processo de interiorização implica sempre internalização da objetividade, o que ocorre certamente de forma subjetiva, mas que não pertence exclusivamente ao domínio da individualidade. A relativa homogeneidade dos habitus subjetivos (de classes, de grupo) encontra-se assegurada na medida em que os indivíduos internalizam as representações objetivas segundo as posições sociais de que efetivamente desfrutam (ORTIZ, 1983, p. 17-18).

Para Bourdieu, portanto, o habitus é um sistema de disposições, modos de perceber, pensar, fazer, sentir, que nos levam a um determinado comportamento em uma determinada circunstância. Segundo ele:

[...] a noção de habitus exprime sobretudo a recusa a toda uma série de alternativas nas quais a ciência social se encerrou, a da consciência (ou do sujeito) e do inconsciente, a do finalismo e do mecanicismo, etc. (...) tal noção permitiame romper com o paradigma estruturalista sem cair na velha filosofia ou da consciência, a da economia clássica e do seu homo economicus, que regressa hoje com o nome de individualismo metodológico (BOURDIEU, 2010, p. 61).

Outra dimensão analisada por Bourdieu é a questão do poder. $\mathrm{O}$ poder simbólico opera como estruturante da ordem social e está diretamente relacionado com as noções de capital, violência e dominação simbólica. O poder simbólico tende a estabelecer uma ordem, um sentido no mundo. Ele não é explícito, porém está presente como condicionante da percepção de mundo dos indivíduos. Para que 
funcione, precisa ser reconhecido como legítimo, através de estruturas imperceptíveis de enraizamento de estruturas de dominação, que são dadas historicamente.

O poder simbólico como poder de constituir o dado pela enunciação, de fazer ver e crer, de confirmar ou de transformar a visão de mundo e, deste modo, a ação sobre o mundo, portanto o mundo; poder quase mágico que permite obter o equivalente daquilo que é exercido pela força (física ou econômica), graças ao efeito específico de mobilização, só se exerce se for reconhecido, quer dizer, ignorado como arbitrário (...) O que faz o poder das palavras e das palavras de ordem, poder de manter a ordem ou de a subverter, é a crença na legitimidade das palavras e daquele que as pronuncia, crença cuja produção não é da competência das palavras (BOURDIEU, 2010, p. 61).

Ainda sobre a questão do poder simbólico, violência simbólica e dominação, Bourdieu, no livro A dominação masculina, empreende um análise etnográfica das estruturas objetivas e das formas cognitivas de uma sociedade historicamente situada, a saber, a dos berberes da Cabília, como um instrumento de análise social das relações de gênero naquela sociedade. Temos aqui um exemplo sobre a questão da dominação e do poder simbólico, legitimado, ainda que involuntariamente, e reconhecido pelo oprimido. Para ele:

[...] A primazia universalmente concedida aos homens se afirma na objetividade de estruturas sociais e de atividades produtivas e reprodutivas, baseadas em uma divisão sexual do trabalho de produção e reprodução biológica e social, que confere aos homens a melhor parte, bom como nos esquemas imanentes a todos os habitus (...) $\mathrm{E}$ as próprias mulheres aplicam a toda realidade e, particularmente, às relações de poder em que se vêem envolvidas esquemas de pensamento que são produto da incorporação dessas relações de poder e que se expressam nas oposições fundantes da ordem simbólicas (BOURDIEU, 1990, p. 45).

Outro aspecto que gostaríamos aqui de destacar diz respeito à relação de Bourdieu com a História. Num debate publicado pela Revista 
Topoi, o historiador Roger Chartier (2002) destaca a contribuição de Bourdieu para o desenvolvimento de um campo específico, a história cultural, bem como para o desenvolvimento de uma visão histórica de todas as ciências sociais. Tendo como referência o livro As Regras da Arte, gênese e estrutura do campo literário, Chartier afirma que:

[...] Bourdieu sublinhará dois elementos: o da necessidade de desenvolver uma sociologia genética que seja capaz de reconstruir, para cada momento histórico particular, como estas categorias ou outras foram definidas, de maneira que não sejam pensadas como universais, invariáveis, invariantes. A partir deste momento, trata-se de reintroduzir a dimensão histórica destas categorias que consideramos espontaneamente como universais, definir em que contexto, por quais razões foram estabelecidas e marcar a impossibilidade de utilizá-las retrospectivamente sem precaução e sem risco de anacronismo. A segunda questão deste livro de Bourdieu é dizer que esta sociologia genética é necessariamente uma forma de pensar relacional, um pensamento relacional. A obra, o artista, o filósofo só existem dentro de uma rede de relações visíveis ou invisíveis que definem a posição de cada um em relação à posição dos outros, ou seja, a uma posição social, em relação a uma posição estética (CHARTIER, 2002, p. 139).

Aqui, Chartier destaca a importância do pensamento de Bourdieu no que diz respeito ao seu aspecto relacional, dos agentes no campo, as regras, os princípios de hierarquia, bem como as disputas, as oposições entre os atores que são os membros desse campo. Chartier destaca ainda a importância do conceito de campo para o desenvolvimento da história social, na medida em que é um conceito que se interpõe entre as determinações socioeconômicas. Ainda sobre esta questão, há uma passagem de Bourdieu, que acreditamos ser bastante pertinente:

Sempre que se institui um destes universos relativamente autônomos, campo artístico, campo científico ou esta ou aquela das suas especificações o processo histórico aí instaurado desempenha o mesmo papel de abstractror de quinta-essência. Donde a análise da história do campo ser, 
em si mesma, a única forma legítima de análise de essência. (BOURDIEU, 2010, p. 71).

Dessa forma, procuramos destacar aqui alguns pontos da sociologia de Bourdieu que podem contribuir para a compreensão do próximo aspecto que abordaremos, que é a relação das ideias de Bourdieu com o pensamento de Émile Durkheim, buscando identificar aproximações e distanciamentos na perspectiva do primeiro com relação à obra do segundo.

\section{Durkheim e Bourdieu}

Vimos anteriormente, alguns dos principais aspectos do pensamento de Durkheim e Bourdieu. Nesse ponto, buscaremos as aproximações e os distanciamentos possíveis entre os autores. A nossa perspectiva de análise partirá das reflexões de Bourdieu, buscando estabelecer os níveis de interlocução possíveis, bem como as permanências e rupturas deste último com relação às ideias do primeiro.

O primeiro ponto que gostaríamos de destacar diz respeito à questão do racionalismo, da aplicação metódica da razão e do racionalismo. Ambos nutriam uma "fé" e um amor grande pela ciência, uma crença no seu valor e na sua missão social. Esse sentimento se expressa no vigor com que advogam seus pontos de vista tanto quanto mais fortemente são contestados. Bourdieu assume uma postura semelhante a Durkheim, segundo a qual a pesquisa sociológica não deve servir apenas como interesse especulativo, devendo sempre ser crítica, com métodos e procedimentos específicos e passíveis de serem replicados.

Bourdieu apreende da teoria de Durkheim a ênfase que este dá a sociedade como elemento que estrutura as práticas individuais. No entanto, afasta-se do excesso de objetivismo de Durkheim, quando 
aponta para as práticas individuais enquanto elementos estruturados. À perspectiva marcadamente positivista de Durkheim de apresentar os fatos sociais como "coisas" buscando um afastamento dos objetos analisados, Bourdieu opõe a necessidade de superação de um universalismo atemporal. Para Bourdieu, apesar da necessidade de um afastamento, não se deve desconsiderar também o contexto, a experiência de vida e social do pesquisador.

Segundo Renato Ortiz (1983), a noção de habitus cumpre um papel fundamental, na medida em que seria, em grande parte, responsável por equacionar a dicotomia indivíduo/sociedade. Segundo ele:

\begin{abstract}
Quando se considera que a prática se traduz por uma 'estrutura estruturada predisposta a funcionar com estrutura estruturante', explicita-se que a noção de habitus não somente se aplica à interiorização das normas e valores, mas inclui os sistemas de classificações que preexistem (logicamente) às representações sociais. O habitus pressupõe um conjunto de 'esquemas generativos' que presidem a escolha; eles se reportam a um esquema de classificação que é, logicamente, anterior à ação. Neste ponto, Bourdieu recupera a análise que Durkheim e Mauss fazem das classificações primitivas. (...) Não é por acaso que Bourdieu privilegia a obra pedagógica de Durkheim; aí vamos encontrar desenvolvidos de forma mais explícita os argumentos avançados sobre o sistema de classificações primitivos (ORTIZ, 1983, p. 16).
\end{abstract}

Sobre esse sistema, Bourdieu também opera com a noção de pares que se opõem, a partir dos objetos do cosmos totêmico (DURKHEIM, 1996), a fim de demonstrar que os esquemas de pensamento que produzem e são produzidos por ele, seguem um mesmo padrão também na sociedade moderna, materializados nos gostos e nas práticas sociais, que são distintos e distintivos.

Assim, no caso da França dos anos 1970, estudado por Bourdieu, temos o seguinte: quem bebe champanha - 
privilegiadamente os patrões urbanos - não se define, no espaço social, apenas por tomar o champanha, mas também e sobretudo pelo fato de preferir a champanha ao uísque (isto é, em oposição aos intelectuais), ao vinho tinto (isto é, em oposição aos empregados rurais) e à cerveja (em oposição ao proletariado urbano), e assim sucessiva e reciprocamente. Tal estrutura social vai reproduzir-se em todos os domínios da prática, desde a escolha dos automóveis, até a prática de esporte, porque a posição ocupada na estrutura é internalizada pelos indivíduos sob a forma de habitus, princípios de ação e de pensamento que funcionam na base daquelas oposições (SILVEIRA, 2006, p. 04).

No prefácio do livro The Making of English Working Class, o historiador britânico Edward P. Thompson nos explica os motivos pelos quais optou pela expressão "making of", ou o "fazer-se”.

Este livro tem um título um tanto desajeitado, mas adequado ao seu propósito. Fazer-se, porque é um estudo sobre um processo ativo, que se deve tanto à ação humana como aos condicionamentos. A classe operária não surgiu tal como o sol numa hora determinada. Ela estava presente ao seu próprio fazer-se (THOMPSON,1987, p. o9).

Acreditamos que aqui esteja presente algo daquilo que discutimos ao longo do trabalho e que está fortemente presente nas reflexões de Bourdieu. O “fazer-se” de Thompson revela, a interlocução, a relação dialética entre a agência e a estrutura, num processo de construção constante. Segundo Chartier:

E é a razão pela qual o conceito de representação que Bourdieu utiliza, o conceito de classificação - de luta de representação, de luta de classificação - se tornou uma categoria essencial, porque permite instalar a análise dentro da herança da sociologia e da antropologia fundadora de Mauss e de Durkheim. E a categoria de representações coletivas, tal como foi definida por Durkheim e Mauss, aponta para a incorporação, dentro do indivíduo, do mundo social a partir de sua própria posição dentro deste mundo, como se as categorias mentais fossem resultado da incorporação das divisões sociais e definissem para cada indivíduo a maneira de classificar, falar ou atuar (CHARTIER, 2002, p. 152). 
A definição do ser social, assim, é dada não apenas a partir de condições objetivas que definem as categorias sociais, mas pelo ser que é percebido por si mesmo e pelos outros.

Nesse sentido, a partir das noções de habitus, campo, capital cultural e poder simbólico, Bourdieu dá uma enorme contribuição aos estudos das relações sociais no campo das ciências humanas como um todo. À crítica que se faz de que essa perspectiva seria "reprodutivista” e encerraria a capacidade transformadora e, sobretudo, a própria "historicidade da História”, Chartier responde:

\footnotetext{
Não é justo dizer, nesse sentido, que Bourdieu nunca tratou da possível destruição da reprodução desses mecanismos: é claro que isso faz parte de sua análise, baseada nos mecanismos que asseguram a reprodução da dominação nas condições que permitem, num certo momento histórico dado, uma ruptura com esta dominação (CHARTIER, 2002, p. 155).
}

Nesse sentido, haverá sempre a possibilidade de um esgarçamento do tecido social, seja através de uma ruptura brutal, ou na medida em que os dominados podem usar progressivamente o que haviam incorporado. Segundo Chartier, Bourdieu não faz claramente uma aposta numa destas duas opções, uma vez que estava imerso na descrição analítica das forças e dos mecanismos que sustentam a reprodução da dominação. Para ele, esse seria o motivo pelo qual exista algo de "melancólico" no trabalho de Bourdieu.

\section{Considerações finais:}

Assim, vimos como o trabalho de Bourdieu está marcado pelas ideias de Durkheim, ainda que seja para superá-las na busca pela construção de uma “teoria da ação", arcabouço teórico que será de grande importância para análises sociológicas futuras. 
Apontamos a "fé" na ciência, ou seja, a crença na construção da Sociologia como uma ciência com procedimentos e métodos específicos passíveis de serem replicados, estruturando um método próprio de reflexão, constitui-se num dos pontos de aproximação entre os autores. A análise a partir de pares de opostos, bem como a busca por leis gerais que regem o universal social, também podem ser apontados como pontos de aproximação.

Discutimos também de que forma Bourdieu avança para além das reflexões de Durkheim, fortemente marcadas pelo Positivismo, articulando estrutura e agência sobretudo a partir das noções de habitus e campo, recuperando o papel do agente social nos processos e dinâmicas socias. O ser social é assim definido não por condições objetivas que definem as categorias sociais, mas por uma definição de si próprio, através de um processo de internalização e externalização das estruturas sociais que são ao mesmo tempo estruturantes e estruturadas.

Dessa forma, percebemos como as ideias de Durkheim, tendo sempre como referencial o contexto em que foram produzidas, contribuíram e ainda contribuem para as construções teóricas de autores contemporâneos. Nesse sentido, preserva sua relevância, colocando-se como um dos "clássicos" fundamentais para todos aqueles que se debruçam sobre a compreensão e reflexão do social.

\section{REFERÊNCIAS}

BELLAH, Robert N. American Sociological Review. v. 24, n. 04, agosto de 1959. p. 448. Disponível em: <https://www.jstor.org/stable/2089531?seq=2\#page_scan_tab_contents $>$. Acesso em 10/o6/2018.

BOURDIEU, Pierre. O Poder Simbólico. Rio de Janeiro, Bertrand Brasil, 2010.

. A Dominação Masculina. Rio de Janeiro, Bertrand Brasil, 1990. 
CATANI, A. M.; NOGUEIRA, M. A. et al. (org.). Vocabulário Bourdieu. Belo Horizonte: Autêntica Editora, 2017.

CHARTIER, Roger. Pierre Bourdieu e a história. Revista Topoi, Rio de Janeiro, mar. 2002, p. 139-182. Disponível em: $<$ revistatopoi.org/numeros_anteriores/Topoio4/topoi4db.pdf $>$. Acesso em 10/o6/2018.

DURKHEIM, Émile. As regras do método sociológico. São Paulo: Companhia Editorial Nacional, 1995.

Educação e Sociologia. Petrópolis: Vozes, 2011.

. Filosofia Moral. Rio de Janeiro: Forense Universitária, 2015.

O Suicídio. Estudo de Sociologia. São Paulo: Martins Fontes, 2000.

. As Formas elementares da vida religiosa, o sistema totêmico na Austrália. São Paulo: Martins Fontes, 1996.

ORTIZ, R. (org.). Pierre Bourdieu: Sociologia. São Paulo: Ática, 1983.

SILVEIRA, Gabriel. A Herança estruturalista de Durkheim nas Ciências Sociais. Ciências Sociais Unisinos, setembro/dezembro de 2006, p. 04. Disponível em: <revistas.unisinos.br/index.php/ciencias_sociais/article/view/6031/3205> . Acesso em 10/06/2018.

THIRY-CHERQUES, H. R. Pierre Bourdieu: a teoria na prática. Rev. Adm. Pública, Rio de Janeiro, v. 40, n. 1, jan./fev., 2006, p. 27-55.

THOMPSON, E. P. A Formação da Classe Operária Inglesa. v. I. Rio de Janeiro: Paz e Terra, 1987.

WACQUANT, L. J. D. Durkheim e Bourdieu: a base comum e suas fissuras. Novos Estudos, n. 48, 1997.

ZOLA, Émile. Germinal. Rio de Janeiro: Abril Cultural, 1972. 